\title{
Epidemiology of Brachial Plexus Injury in North Indian Tertiary Care Hospital: A Retrospective Study
}

\section{ABSTRACT}

Introduction: Epidemiological studies on Brachial Plexus Injuries (BPI) are in limited numbers. Such epidemiological factors can be different in different countries.

Aim: To determine the epidemiological factors on brachial plexus injuries in North Indian tertiary care hospital.

Materials and Methods: A retrospective observational study was conducted in which all patients of brachial plexus injury who underwent surgery for same in Department of Plastic Surgery of a tertiary care hospital in Lucknow, Uttar Pradesh, India from January 2017 to December 2019 were included. Those who were managed conservatively were excluded from study. Their demographic and epidemiological factors like type of injury, limb involvement, nature of trauma were evaluated. Data was tabulated and results were expressed in terms of numbers and percentages.

Results: There were total 221 patients, out of which 147 patients had pan brachial plexus involvement and 74 patients suffered from partial involvement of brachial plexus roots. Majority of the patients had their right upper limb involved $(n=139)$. Motor cycle accidents $(n=155)$ were the primary cause followed by four wheeler accident $(n=25)$ and fall from height $(n=18)$.

Conclusion: Brachial plexus injury is a challenge for surgeons. Road Traffic Accidents are the dominant cause of these injuries and among them motorcycle accidents remained the major cause.

Keywords: Hand injuries, Head injuries, Post-traumatic injuries, Road traffic accidents

\section{INTRODUCTION}

Brachial plexus injury leads to neurological dysfunctions in the affected individuals [1]. Clinical examination alone is not sufficient to determine the level and severity of injury. Electrodiagnostic studies, sensory and motor nerve conduction studies are helpful in determining the diagnosis, prognosis and in guiding further rehabilitative measures. Electromyography has an additional role in documenting recovery [1].

The most common causes of BPI are traumas caused by road traffic accidents. Motorcycle accidents are predominant cause of such injuries [2]. Among the mechanisms leading to injury, both traction and/or compression forces have been identified as causes, with traction forces causing major injuries (>95\%) [3].

According to Barnes R, motorcycle crashes cause most traction injuries of the brachial plexus [4]. In traction injuries, the important factor is forceful separation of the neck and shoulder or upper arm and trunk. According to Barnes R and Leffert RD, the roots of the plexus being affected mostly depends on the attitude of the upper limb during the time of impact [4,5]. Road traffic accidents are a high kinetic energy trauma; therefore, these patients are more prone to sustain multiple root avulsions [6].

An understanding of the types and patterns of such injuries in a given geographical region is essential to assess related health economics and plan for primary prevention. A review of current literature showed that data on level and severity of BPIs are lacking in India despite having a large number of BPI cases. This study helps to find the various epidemiological factors causing these injuries and strengthen the current database to prevent and treat further such injuries.

\section{MATERIALS AND METHODS}

A retrospective observational study was done in the Department of Plastic Surgery, King George's Medical University, Lucknow, Uttar
Pradesh, India in July 2020. The data of patients admitted from January 2017 to December 2019 was gathered and studied.

Inclusion criteria: All patients who underwent surgery for brachial plexus injuries during the period of study were taken up for evaluation and form the sample population.

Exclusion criteria: Patients who were on conservative management or had their multiple admissions were excluded from study.

In the three years of study (2017 to 2019), total 221 cases fulfilled the inclusion criteria and were included in study. Information was collected through retrospectively analysing the record files of patients on demographic aspects such as age and sex. Epidemiological aspects were observed as which limb involved, whether its pan brachial or partial injury, mechanism of injury (traumatic or non traumatic or other).

\section{STATISTICAL ANALYSIS}

Data was entered into Microsoft excel and results were expressed in terms of numbers and percentages.

\section{RESULTS}

Young adults between the age group of 21-30 years constitute $43.43 \%$ of total BPI patient [Table/Fig-1].

\begin{tabular}{|l|c|c|}
\hline Age (in years) & Number & Percentages (\%) \\
\hline $1-10$ & 8 & 3.6 \\
\hline $11-20$ & 51 & 23.07 \\
\hline $21-30$ & 96 & 43.43 \\
\hline $31-40$ & 43 & 19.45 \\
\hline $41-50$ & 14 & 6.3 \\
\hline $51-60$ & 9 & 4.07 \\
\hline $61-70$ & 0 & 0 \\
\hline Total & 221 & 100 \\
\hline [Table/Fig-1]: Age distribution of brachial plexus injury patients. \\
\hline
\end{tabular}


Majority of the patients (62.89\%) had their right upper limb involved. Majority of victims were male in current study. Most patients had pan brachial plexus injury (66.5\%) i.e., involvement of all the roots of brachial plexus of the limb [Table/Fig-2].

\begin{tabular}{|l|c|}
\hline Variables & Total (\%) \\
\hline Side & $139(62.89)$ \\
\hline Right limb & $81(36.65)$ \\
\hline Left limb & $1(0.45)$ \\
\hline Bilateral & $205(92.76)$ \\
\hline Gender & $16(7.23)$ \\
\hline Male & \\
\hline Female & $147(66.51)$ \\
\hline Type of injury & $74(33.48)$ \\
\hline Pan brachial plexus injury & \\
\hline Partial brachial plexus injury & \\
\hline [Table/Fig-2]: Epidemiology of Brachial Plexus Injury. (N=221).
\end{tabular}

Trauma was the primary cause of brachial plexus injury in $98 \%$ cases $(n=217)$. Only four cases had birth brachial plexus palsy due to unknown aetiology.

Motor cycle accidents were the primary cause followed by four wheeler accident and fall from height. There were no cases of non traumatic brachial plexus injury during the study period [Table/Fig-3]

\begin{tabular}{|l|c|c|c|}
\hline Causes & Pan brachial & Partial & Total \\
\hline Traumatic injury & \multicolumn{3}{|l|}{} \\
\hline Motorcycle accidents & $110(49.77 \%)$ & $45(20.36 \%)$ & $155(70.14 \%)$ \\
\hline Four-wheeler accident & $15(6.78 \%)$ & $10(4.52 \%)$ & $25(11.31 \%)$ \\
\hline Fall from height & $10(4.52 \%)$ & $8(3.62 \%)$ & $18(8.14 \%)$ \\
\hline Sharp weapon injury & $3(1.35 \%)$ & $4(1.81 \%)$ & $7(3.17 \%)$ \\
\hline Gunshot injury & $7(3.17 \%)$ & $5(2.26 \%)$ & $12(5.43 \%)$ \\
\hline Total & $145(65.61 \%)$ & $72(32.58 \%)$ & $217(98.12 \%)$ \\
\hline Other & $147(66.51 \%)$ & $74(33.48 \%)$ & $221(100 \%)$ \\
\hline Birth brachial plexus injury & $2(0.9 \%)$ & $2(0.9 \%)$ & $4(1.81 \%)$ \\
\hline Total & [Table/Fig-3]: Mechanism of injury of brachial plexus injury. \\
\hline
\end{tabular}

Vascular injuries were seen in 14 and muscle or tendon injury in 12 patients. Five patients had associated fractures of clavicle, upper limb bones and ribs and four patients have abdominal injury.

\section{DISCUSSION}

Epidemiological studies of brachial plexus injuries have been published all over the world with different parameters and results. There are such studies been published in the context of Indian patients also through various institutes over time. The most common scenario in Indian continent is of a young man injured in a motorcycle accident [7].

Kim DH et al., USA studied the outcome of surgery in 1019 brachial plexus lesions but this study included tumours and thoracic outlet syndrome [8]. The study conducted by Jain DK et al., involved only post-traumatic brachial plexus injuries and did not include iatrogenic injuries or tumours of the brachial plexus [9].

Young adults between the age group of 20-30 years constituted $43.43 \%$ of total BPI patients in this study, with 205 male and 16 female patients. The study by Jain DK et al., showed the average age of the patient in their study to be 24 years and the age group 21-30 years accounted for $45.7 \%$ of the patients. There were 297 male patients and seven female patients [9].
Majority of the patients 139 (62.89\%) had their right upper limb involved, 81 patients had left upper limb involvement and one patient had bilateral pan brachial plexus injury in our study. Jain DK et al., reported in their study 212 (69.9\%) right upper limb and 92 left upper limb involvement [9].

Most patients had pan brachial plexus injury 147 (66.5\%) i.e., involvement of all the roots of brachial plexus of the limb and partial injuries accounted for 74 of the total cases studied. Jain DK et al., reported in their study, 146 (48\%) as global injuries [9].

Jain DK et al., reported in their study, 54\% (164) of patients had some associated injuries while 46\% (140) had isolated brachial plexus injury [9]. We found vascular injuries in 14 patients and muscle or tendon injury in 12 patients. Five patients had associated fractures of clavicle, upper limb bones and ribs. Van der Werken C and de Vries $L$ found that $20 \%$ had associated vascular trauma [10].

In study by Jain DK et al., road traffic accidents accounted for $94 \%$ of the brachial plexus injuries and of these 90\% were associated with two wheeler accidents [9]. In present study, trauma was the primary cause of brachial plexus injury in $98 \%$ cases of brachial plexus injury. Only four cases had birth brachial plexus palsy due to unknown aetiology. Motorcycle accidents were the primary cause followed by four wheeler accident and fall from height. Kaiser $\mathrm{R}$ et al., demonstrated that the patient suffering from severe BPI was a male after motorcycle accident with closed supraclavicular injury causing complete or to some extent less frequently upper plexus palsy [11].

This study reflects the epidemiological parameters of brachial plexus injury in a tertiary care teaching hospital. There has been an increasing trend in number of brachial plexus injury cases. Such studies help us to be prepared in treating these patients efficiently by adequately planning the time required for assessment, reducing the surgical time duration, increasing the expertise by training of residents, making available manpower for their counselling, rehabilitation. There is a need to spread awareness about the early treatment.

\section{Limitation(s)}

The study limit's in the duration of the study and a more detailed analysis in the pattern and management of the cases was needed.

\section{CONCLUSION(S)}

This study helps give an overview into the epidemiological aspects of brachial plexus injuries in a tertiary care hospital in north India. Road traffic accidents are the most common mode of traumatic brachial plexus injury.

\section{REFERENCES}

[1] Midha R. Epidemiology of brachial plexus injuries in a multitrauma population. Neurosurgery. 1997:40(6):1182-88.

[2] Yoshikawa T, Hayashi N, Yamamoto S, Tajiri Y, Yoshioka N, Masumoto T, et al. Brachial Plexus Injury: Clinical Manifestations, Conventional Imaging Findings, and the Latest Imaging Techniques. Radiographics. 2006;26:133-43.

[3] Altaf F, Mannan K, Bharania P, Sewell M, Di Mascio L, Sinisi M. Severe brachial plexus injuries in rugby. Injury. 2012;43:272-73.

[4] Barnes R. Traction injuries of the brachial plexus in adults. The Journal of Bone and Joint Surgery British Volume. 1949;31(1):10-16.

[5] Leffert RD. Brachial-plexus injuries. New England Journal of Medicine. 1974;291(20):1059-67.

[6] Chuang T, Chiu F, Tsai Y, Chiang S, Yen D, Cheng $H$. The comparison of electrophysiologic findings of traumatic brachial plexopathies in a tertiary care center. Injury. 2002;33:591-95.

[7] Thatte MR, Babhulkar S, Hiremath A. Brachial plexus injury in adults: Diagnosis and surgical treatment strategies. Ann Indian Acad Neurol. 2013;16:26-33

[8] Kim DH, Cho YJ, Tiel RL, Kline DG. Outcomes of surgery in 1019 brachia plexus lesions treated at Louisiana State University Health Sciences Center. $J$ Neurosurg. 2003;98:1005-16. 
[9] Jain DK, Bhardwaj P, Venkataramani H, Sabapathy SR. An epidemiological study of traumatic brachial plexus injury patients treated at an Indian centre. Indian J Plast Surg. 2012;45(3):498-503.

[10] Van der Werken C, de Vries L. Brachial plexus injury in multitraumatized patients. Clinical Neurology and Neurosurgery. 1993;95:30-32.
[11] Kaiser R, Waldauf P, Ullas G, Krajcová A. Epidemiology, etiology, and types of severe adult brachial plexus injuries requiring surgical repair: Systematic review and meta-analysis. Neurosurgical Review. 2018;43(2):443-52.

\section{PARTICULARS OF CONTRIBUTORS:}

1. Senior Resident, Department of Plastic Surgery, King George's Medical College, Lucknow, Uttar Pradesh, India.

2. Senior Resident, Department of Plastic Surgery, King George's Medical College, Lucknow, Uttar Pradesh, India.

3. Additional Professor, Department of Plastic Surgery, King George's Medical College, Lucknow, Uttar Pradesh, India.

4. Professor, Department of Plastic Surgery, King George's Medical College, Lucknow, Uttar Pradesh, India.

\section{NAME, ADDRESS, E-MAIL ID OF THE CORRESPONDING AUTHOR:}

Dr. Sandesh Singh,

E-mail: dr.sndsh@gmail.com
Department of Plastic Surgery, KGMU, Chowk, Lucknow, Uttar Pradesh, India.

\section{PLAGIARISM CHECKING METHODS: Jain Het al.]}

- Plagiarism X-checker: Jun 25, 2021

- Manual Googling: May 22, 2021

- iThenticate Software: Jul 17, 2021 (15\%)
ETYMOLOGY: Author Origin

\section{AUTHOR DECLARATION:}

- Financial or Other Competing Interests: None

- Was Ethics Committee Approval obtained for this study? Yes

- Was informed consent obtained from the subjects involved in the study? Yes

- For any images presented appropriate consent has been obtained from the subjects. No
Date of Submission: Mar 06, 2021 Date of Peer Review: May 24, 2021 Date of Acceptance: Jun 29, 2021 Date of Publishing: Oct 01, 2021 